\title{
Dynamical study of a tropical cut-off low over South Africa, and its impact on tropospheric ozone
}

\author{
J.L. Baray ${ }^{\mathrm{a}, \mathrm{b}, *}$, S. Baldy ${ }^{\mathrm{a}}$, R.D. Diab ${ }^{\mathrm{c}}$, J.P. Cammas ${ }^{\mathrm{d}}$ \\ a Laboratoire de Physique de l'Atmosphère (LPA), CNRS-UMR 8105, Université de la Réunion, 15 Av. René Cassin, BP 7151, \\ 97715 Saint-Denis Messag. Cedex 9, La Réunion 97715, France \\ ${ }^{\mathrm{b}}$ Institut Pierre Simon Laplace (IPSL), Observatoire de Physique de l'Atmosphère de la Rèunion (OPAR), La Réunion, France \\ ${ }^{\mathrm{c}}$ School of Life and Environmental Sciences, University of Natal, Dalbridge 4041, South Africa \\ ${ }^{\mathrm{d}}$ Laboratoire d'Aérologie (LA), CNRS-UMR 5560, Observatoire Midi-Pyrénées, 14 Av. Edouard Belin, 31400 Toulouse, France
}

The structure and evolution of an intense tropical cut-off low (COL) occurring over South Africa is documented, by combining meteorological and ozone data $\mathrm{f}$ rom a number of dif $\mathrm{f}$ erentsources, such as in situ radiosoundings, Measurement of ozone and water vapor by airbus in-service aircraft data, satellite (Meteosat) and modelled European Center for Medium-Range Weather Forecast data. The COL extends to latitude $10^{\circ} \mathrm{S}$, with a lifetime of approximately 2 weeks, and a horizontal size ofabout $10^{\circ}$. A distinguishing feature of this case study is that it becomes detached from the stratospheric reservoir in both the vertical and horizontal planes, in an irreversible way and as such is different in structure to a mid-latitude or a polar COL. Consequently, even though tropical COLs may occur inf requently, it is likely that the tropospheric ozone enhancement induced by this irreversible intrusion could be significant.

Keywords: Tropical tropospheric dynamics; Southern Hemisphere; Stratosphere-troposphere exchange; Tropospheric ozone; Airborne measurements; Radiosounding

\section{Introduction}

A cut-off low (COL) is an upper tropospheric trough of air coming from the stratosphere, which becomes isolated from its external environment and is advected equatorward of the mid-latitude westerlies. This kind of feature is of dual importance: on the one hand, it plays a significant role in the tropospheric ozone balance through dissipation and mixing of stratospheric ozone; and on the other, it is important in terms of the weather it produces through the disturbance of flow in the upper

*Corresponding author. Laboratoire de Physique de l'Atmosphère (LPA), CNRS-UMR 8105, Université de la Réunion, 15 Av. René Cassin, BP 7151, 97715 Saint-Denis Messag. Cedex 9, La Réunion 97715, France. Tel.: + 262-26296-86-64; fax: + 262-262-93-86-65.

E-mail address: baray@univ-reunion.fr (J.L. Baray). troposphere, the formation of jet-streams and its role in convective activity which is often triggered by lower static stability under the COL and/or by potential vorticity advection on the down-shear side of the COL.

COLs are well-known mechanisms in the middle and polar latitudes. Many studies of polar and mid-latitude COLs have been published in recent years: for example, modelling of COL case studies and tropopause folds (Ebel et al., 1991; Langford et al., 1996), impact of COLs on tropospheric ozone (Ancellet et al., 1994), and a mesoscale analysis of the decay of a COL (Ravetta and Ancellet, 2000; Gouget et al., 2000). Most of these studies have focused on mid-latitude COLs; however, it has been noted that they may extend quite far towards the equator (Kentarchos et al., 1998, 1999).

In their statistical study of the size and distribution of COL systems, Price and Vaughan (1992) identified three types of COL, depending on the location of the 
detachment: polar vortex, polar, and subtropical. Polar COLs, which usually extend to mid-latitude regions, are the most studied systems. According to that study, subtropical COLs are smaller than the two other types, and their lifetime is shorter. The authors concluded that, a priori, subtropical COLs do not play a significant role in the tropospheric ozone budget.

However, Barsby and Diab (1995) analyzed the relationship between ozone and synoptic weather systems, for different situations including a case of a subtropical COL over South Africa. By using the analysis of daily total ozone mapping system (TOMS) and European Center for Medium-Range Weather Forecast (ECMWF) data (geopotential heights and potential vorticity fields), they highlighted the importance and the strength of the link between ozone and day-to-day weather systems in cases of COLs and subtropical anticyclones. The observation of the synoptic weather context of another case study of a COL over Australia has also been reported (Griffiths et al., 1998).

Despite these studies, the literature, which is very rich in case studies of polar COLs, is deficient when it comes to case studies of subtropical COLs. The objective of this paper is to document a case of a tropical COL, which occurred over South Africa during October 1996. By using instrumental data sets (Measurement of OZone and water vapor by Airbus In-service airCraft, MOZAIC, flights from Vienna to Johannesburg and radiosoundings over Reunion Island), satellite (Meteosat and
TOMS) and global model data (ECMWF), we shall characterize the manner in which this tropical COL differs from a typical COL based on case studies from the polar latitudes. Aspects such as their dynamics and tropospheric ozone influence will be considered.

\section{Synoptic situation before the formation of the COL}

In this section, we shall examine the synoptic situation before the formation of the COL and its detachment from the mid-latitude regime using ECMWF analysis $\left(1^{\circ}\right.$ grid, 15 vertical pressure levels between 1000 and $10 \mathrm{hPa}$ and $6 \mathrm{~h}$ time resolution). A Rossby wave intensified over the southern part of Africa, at the latitude of the subtropical jet-stream, at the end of September 1996. The associated potential vorticity (PV, we use the absolute value in the Southern Hemisphere) disturbance propagated towards the east, and reached Reunion Island $\left(21^{\circ} \mathrm{S}, 55^{\circ} \mathrm{E}\right)$ on 1 October (Fig. 1). The subtropical jet-stream intensified in two jet streaks, south of South Africa and south-east of Reunion Island (wind speed in excess of $60 \mathrm{~m} / \mathrm{s}$ ). As the wave breaking process proceeded, a significant irreversible deformation of isentropic PV contours occurred, ending in isolated PV structures over Africa at $15^{\circ} \mathrm{S}$ in the wake of the wave. This case of Rossby wave breaking (RWB) behaved similarly to the one reported by Scott et al. (2001) over the South Atlantic, ending in the formation

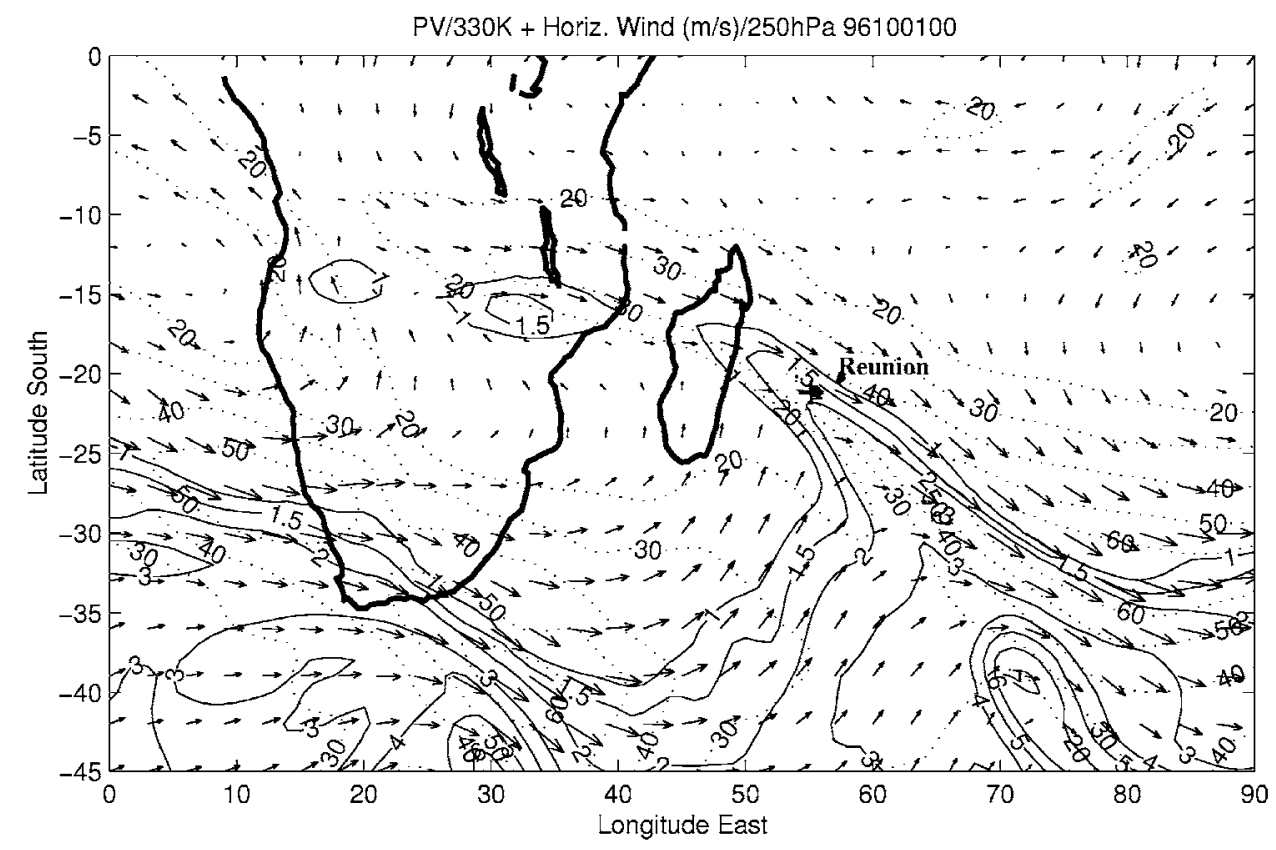

Fig. 1. ECMWF (spherical harmonics T213, 1 degree of resolution in latitude and longitude) horizontal wind field on the isobaric level $250 \mathrm{hPa}$, and PV on the isentropic level $330 \mathrm{~K}$, on 1 October 1996, $00 \mathrm{GMT}\left(1 \mathrm{PVU}=1\right.$ potential vorticity unit $\left.=10^{-6} \mathrm{~m}^{2} \mathrm{~s}^{-1} \mathrm{~K} \mathrm{~kg} \mathrm{~kg}^{-1}\right)$. Reunion Island $\left(55^{\circ} \mathrm{E}, 21^{\circ} \mathrm{S}\right)$ is labelled by a cross. 
of a filament of stratospheric origin, located equatorwards of the mid-latitude regime. The PV structure over Africa that is left behind in the wake of the Rossby wave is called a COL in the following discussion, whilst the PV structure that links the COL to the wave is called the filament.

The vertical perspective of the wave breaking event is further illustrated by an ozone radiosounding performed at Reunion Island (Fig. 2). The values of the ozone mixing ratio in the layer located between 10 and $11 \mathrm{~km}$, are substantially higher ( $>180 \mathrm{ppbv}$ ) than corresponding values in other cases of subtropical tropopause folds reported in the literature ( $80 \mathrm{ppbv}$ for Gouget et al., 1996 and $70 \mathrm{ppbv}$ for Folkins and Appenzeller, 1996). The large vertical thickness of the filament (almost $3 \mathrm{~km}$ from 345 to $360 \mathrm{~K}$ ) is suggesting more of a barotropic event (RWB), than a baroclinic event, which leads to slanted upper level frontogenesis associated with tropopause folds, that are typically $1-1.5 \mathrm{~km}$ deep (Shapiro, 1980). The tropospheric total ozone column derived from the radiosounding is $47.9 \mathrm{DU}$ (tropopause level: $90 \mathrm{hPa}$ ); The ozone filament contribution is $27.9 \mathrm{DU}$ (layer $210-310 \mathrm{hPa}$ ), which represents $58 \%$ of the tropospheric ozone column.

A signature of the RWB event over Reunion Island is also detected in the total column ozone derived from TOMS data which shows an increase of about 14 DU during the event (277.6 DU over Reunion Island on 28 September, before the event; 290.9 DU on 1 October and 291.8 DU on 2 October, during the event; 282.3 DU on 6 October, after the event). The ozone filament at Reunion Island $(11 \mathrm{~km})$ is located $4 \mathrm{~km}$ below the ozonopause $(15 \mathrm{~km})$ and $6 \mathrm{~km}$ below the thermal tropopause $(17 \mathrm{~km})$. It is very likely that in the following days, tropospheric diffusion processes such as gravity waves, convection, turbulence, will contribute to the final stage of an irreversible exchange from the stratosphere to the troposphere. As no data were available to investigate this issue, we will focus the study on the part of the wave that broke over South Africa for which MOZAIC aircraft data are available.

Studies of RWB in the subtropics, such as those based on ECMWF analyses by Postel and Hitchman (1999) and Scott and Cammas (2002), show that this phenomenon is quite frequent and undergoes a seasonal cycle with substantial interannual variability. It emphasizes the importance of investigating further case studies with ozone measurements from radiosondings, lidar systems or from the MOZAIC program to improve our understanding of the tropospheric ozone budget in the subtropics.

\section{Dynamical evolution of the COL and its impact on tropospheric ozone}

The temporal evolution of the COL in the horizontal and vertical planes based on ECMWF data is shown in
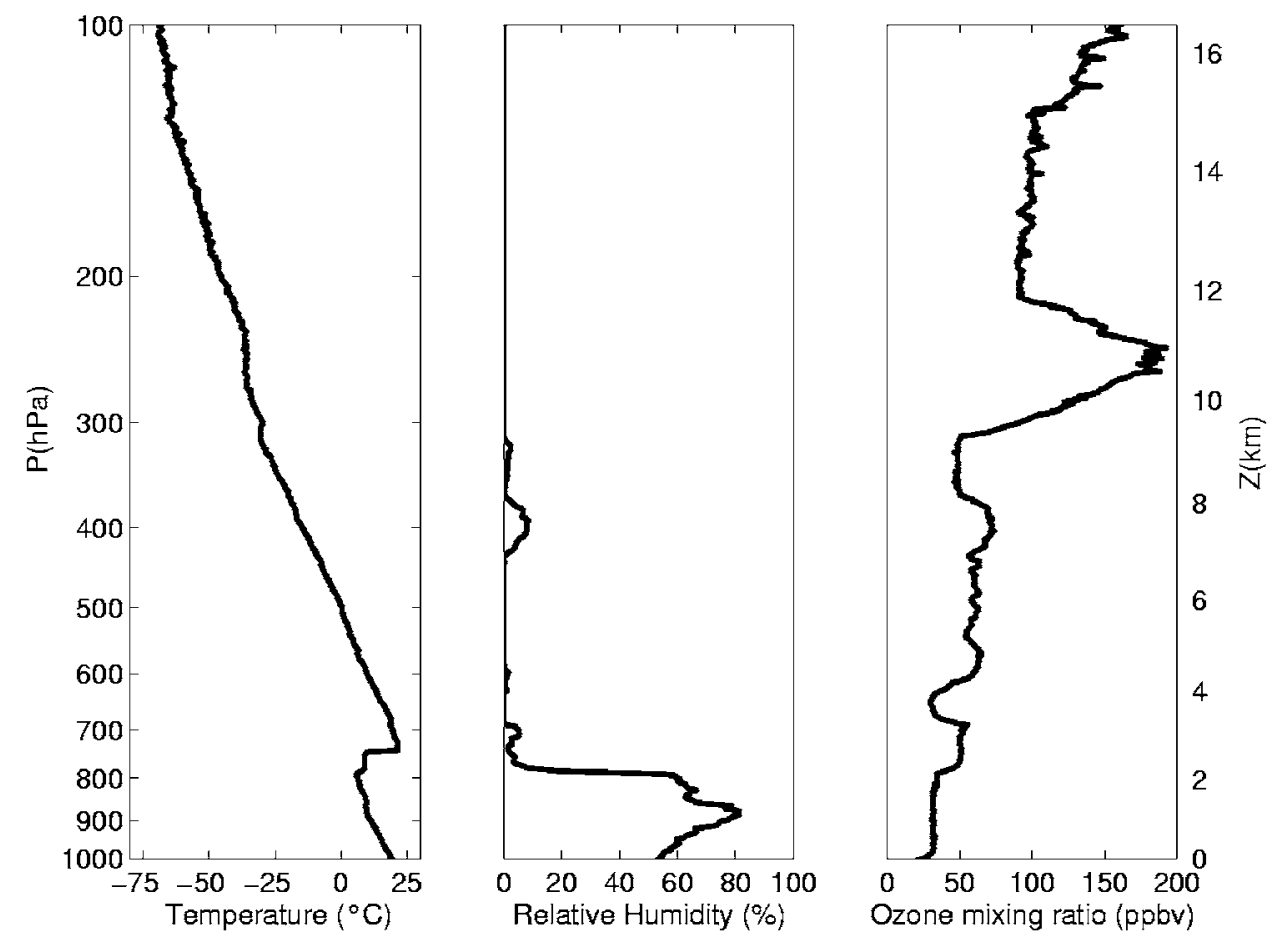

Fig. 2. Temperature $\left({ }^{\circ} \mathrm{C}\right)$, relative humidity $(\%)$ and ozone mixing ratio (ppbv) profiles obtained by radiosounding at Reunion Island on the morning of 1 October 1996. 

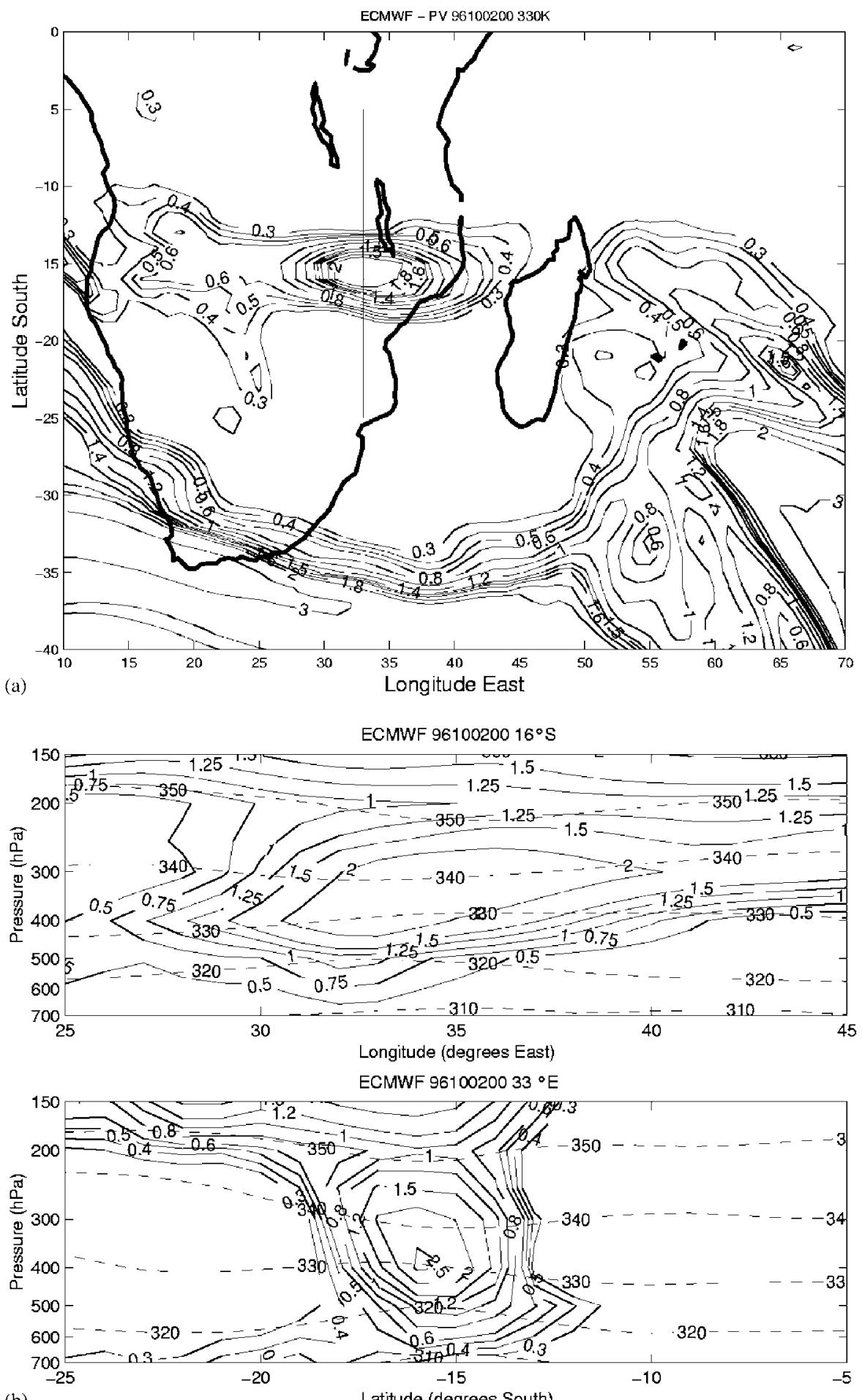

Fig. 3. (a) PV field on the $330 \mathrm{~K}$ surface on 2 October 1996, (b) vertical cross-section of PV along $16^{\circ} \mathrm{S}$ (top) and $33^{\circ} \mathrm{E}$ (bottom) on 2 October 1996, (c) PV field on the $330 \mathrm{~K}$ surface on 7 October 1996, and (d) vertical cross-section of PV along $10^{\circ} \mathrm{S}$ (top) and $36^{\circ} \mathrm{E}$ (bottom) on 7 October 1996. 

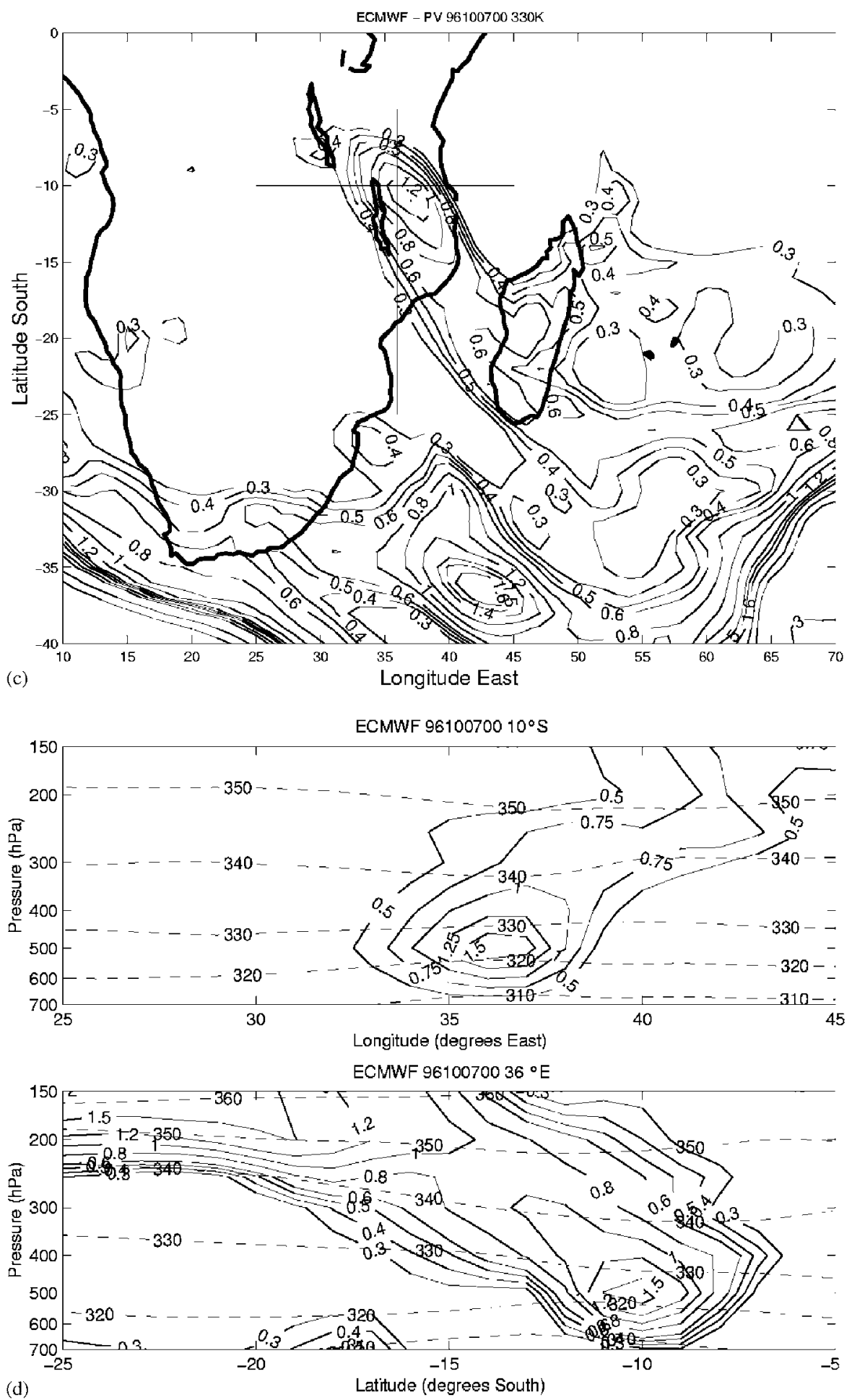

Fig. 3 (continued). 
Evolution of the center of the COL, and of the PV profile at the center (ECMWF data at 00 GMT)

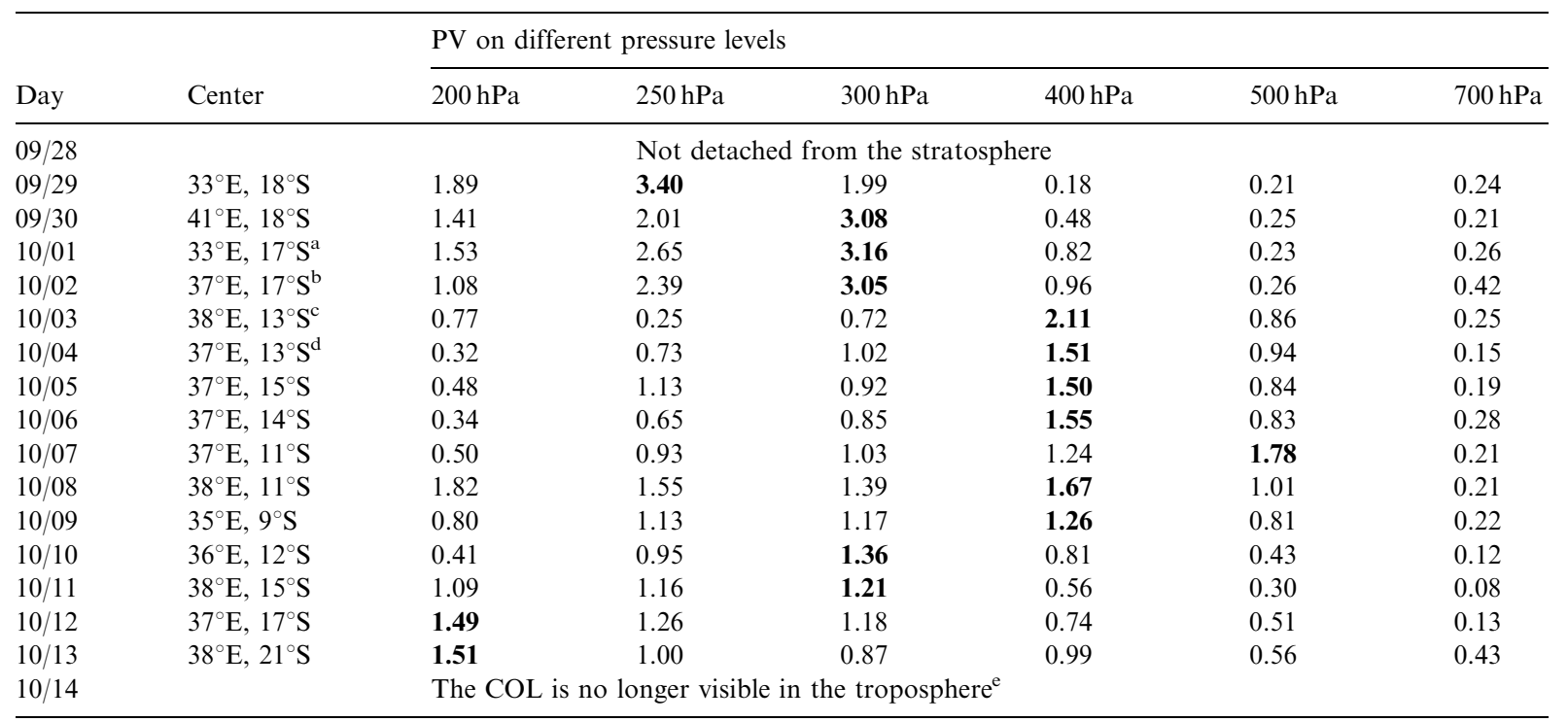

\footnotetext{
${ }^{\mathrm{a}}$ Formation of a secondary $\mathrm{PV}$ maximum at $19^{\circ} \mathrm{E}, 14^{\circ} \mathrm{S}$, whose intensity is lower $(\mathrm{PV}=0.6)$.

${ }^{\mathrm{b}}$ The secondary PV maximum is moving towards the north-east. In the Atlantic Ocean, PV remains under 0.6.

${ }^{\mathrm{c}}$ The secondary PV maximum has dissipated. The COL lengthens (longitude $>$ latitude), inducing another secondary maximum at $24^{\circ} \mathrm{E}, 14^{\circ} \mathrm{S}(\mathrm{PV}=0.7)$.

${ }^{\mathrm{d}} \mathrm{PV}$ over Africa is quite high $(\mathrm{PV}=0.3-0.4)$, but it is difficult to distinguish any secondary maxima (outside of the principal COL).

${ }^{\mathrm{e}}$ After the complete dissipation of the COL, another system appears. It will be completely detached on 17 October, reaching the latitude band $5^{\circ} \mathrm{S}-10^{\circ} \mathrm{S}$ on $18-19$ October, with PV between 0.5 and 1.

The maximum PV value (in PVU) for each profile is indicated in bold type.
}

Fig. 3. After 2 October, the COL is completely detached from the stratosphere, in both the horizontal (Fig. 3a) and the vertical (Fig. 3b) planes. Its center, where the PV value is at a maximum, is located at $16^{\circ} \mathrm{S} ; 33^{\circ} \mathrm{E}$ in the horizontal, and at $400 \mathrm{hPa}$ in the vertical, which corresponds approximately to the $330 \mathrm{~K}$ isentropic level and to an altitude of $8 \mathrm{~km}$. The fact that the air mass is completely cut off from the stratosphere in the vertical plane distinguishes this kind of feature from polar or mid-latitude COLs, in which PV contours on isentropic planes are detached from the general PV field in the horizontal, but not frequently in the vertical plane. The PV fields and the vertical cross-sections on 7 October (Figs. 3c and d) show that the $\mathrm{COL}$ is always quite intense ( $\mathrm{PV}>1.2 \mathrm{PVU}$ in the center of the $\mathrm{COL})$, and continues its northwards and sinking movement. The center is located at $10^{\circ} \mathrm{S} ; 36^{\circ} \mathrm{E}$, and at the $500 \mathrm{hPa}$ pressure level. It is noted that 6 days after its detachment, the air mass did not return to the stratosphere. Notwithstanding the fact that a tropical COL occurs rarely, it is likely to have a significant impact on tropospheric ozone as the majority of the ozone may dissipate in the troposphere.

The evolution of the COL is summarized in Table 1. Until 8 October, the values of PV remain above
1.5 PVU, whereafter, the PVU values diminish but remain above $1 \mathrm{PVU}$ until 13 October. This COL thus had a very long lifetime, compared to the statistics presented by Price and Vaughan (1992). They claimed that $72 \%$ of subtropical COLs have a lifetime less than 3 days, and 98\% less than 6 days. Moreover, on 2 October, the horizontal size of the COL is $6^{\circ}$ in latitude, and $15^{\circ}$ in longitude. This COL thus had a large horizontal extent, compared to the statistics of Price and Vaughan (1992), who stated that $53 \%$ of subtropical COLs have a horizontal diameter less than $5^{\circ}$, and $91 \%$ less than $10^{\circ}$. However, these figures of Price and Vaughan (1992) need to be treated with caution, since they are based on low-resolution data.

The cloud activity associated with the COL is visible on the Meteosat images (Fig. 4). The infrared and water vapor images for the 1 October (simultaneously with the radiosounding over Reunion Island), 8 and 11 October 1996 (simultaneously with the MOZAIC measurement ) are shown in Fig. 4. The streamer of dry air is clearly visible on the water vapor image of 1 October, as a dark filament. The barotropic deformation, which is at the origin of the COL, is associated with an upper level front, visible on the infrared Meteosat images. On 2 October, when the COL is most intense, and when it is 

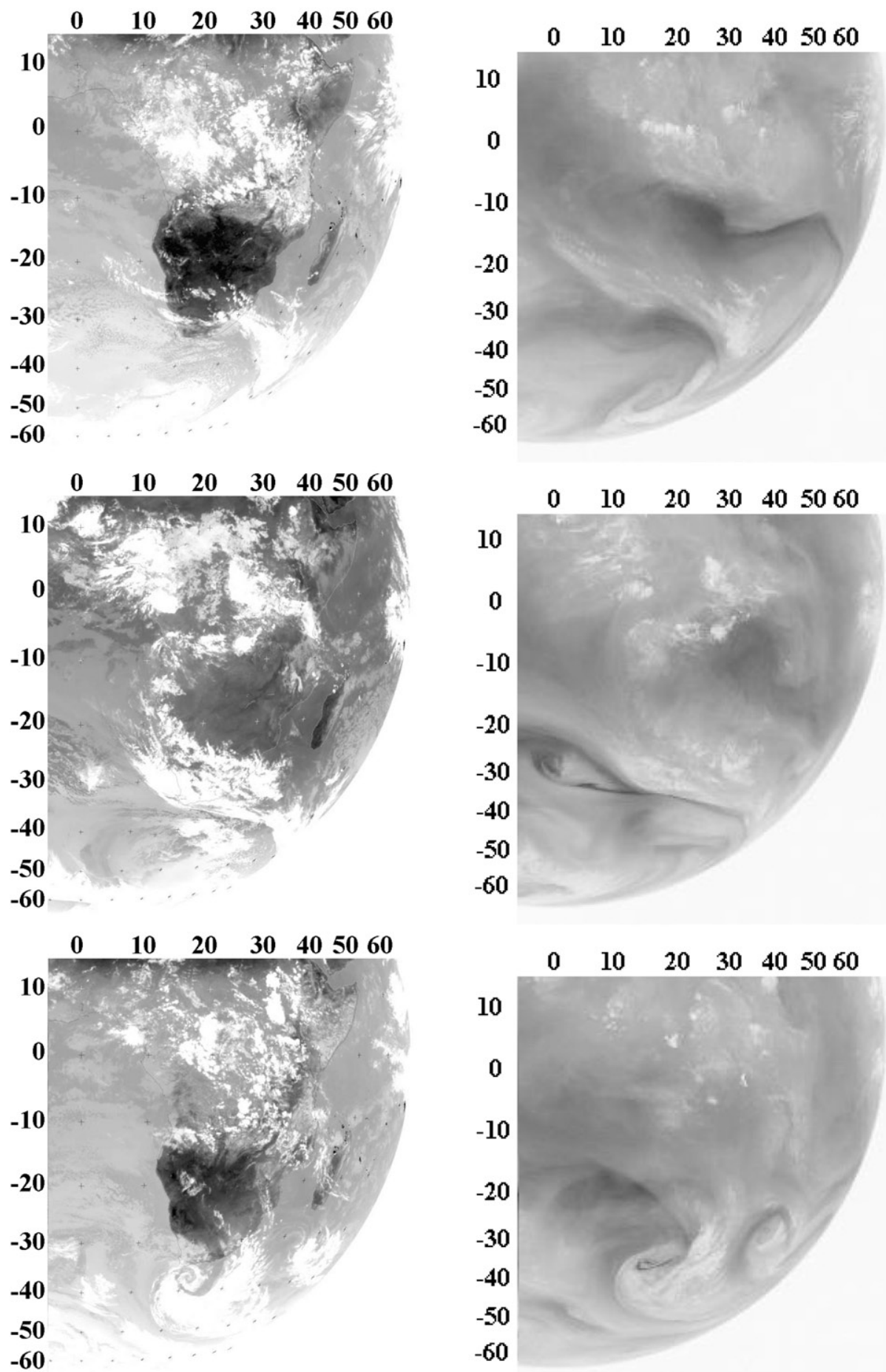

Fig. 4. Meteosat images on 1 October 1996 (top), 8 October (middle), and 11 October (bottom) 12 GMT, in infrared (left) and water vapor (right) channels. Each $10^{\circ}$ in latitude and longitude is marked by crosses on the infrared images. Infrared and visible images are available on the web site http://www-grtr.u-strasbg.fr/ and water vapor images on http://www.eumetsat.de/. 

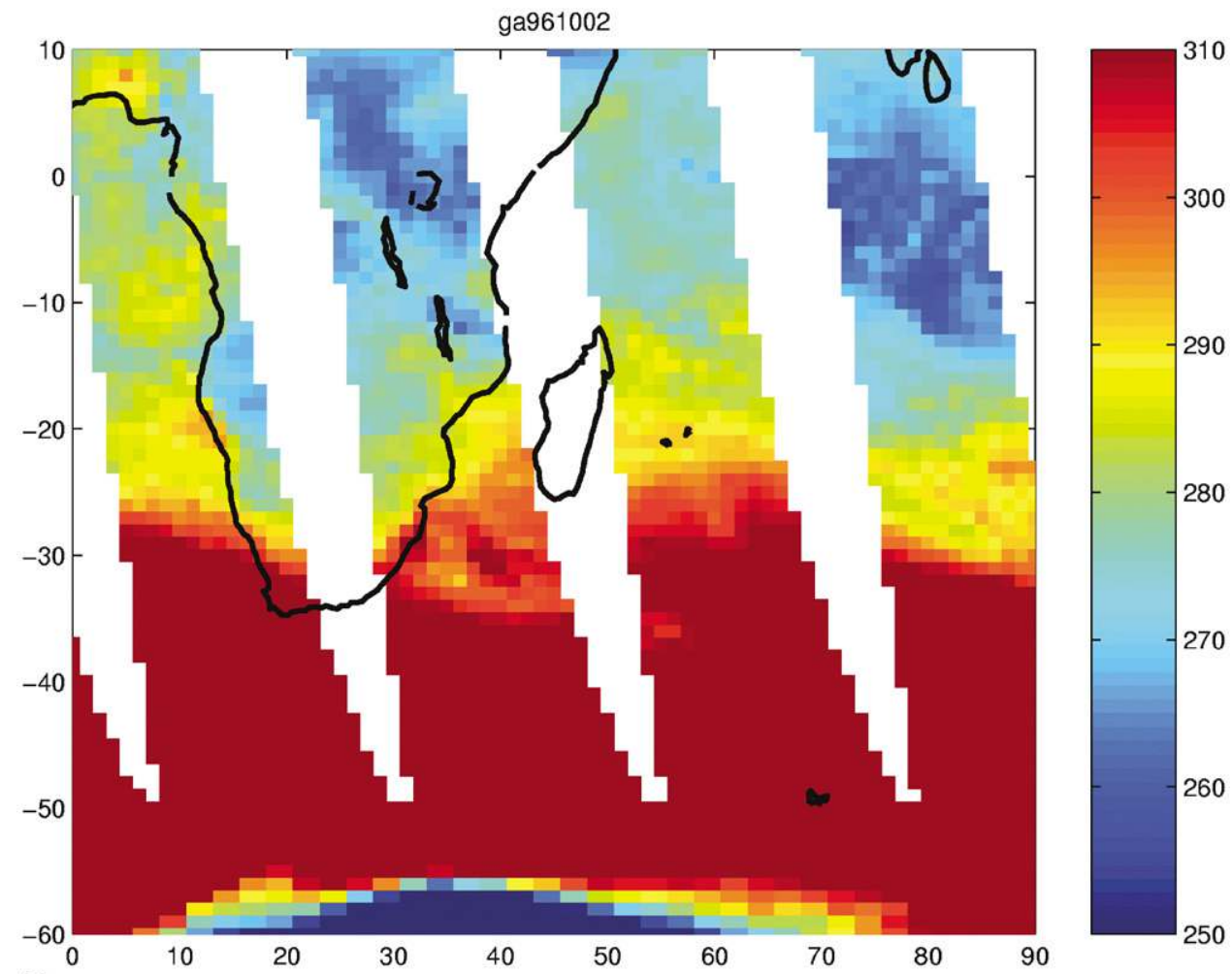

(a)

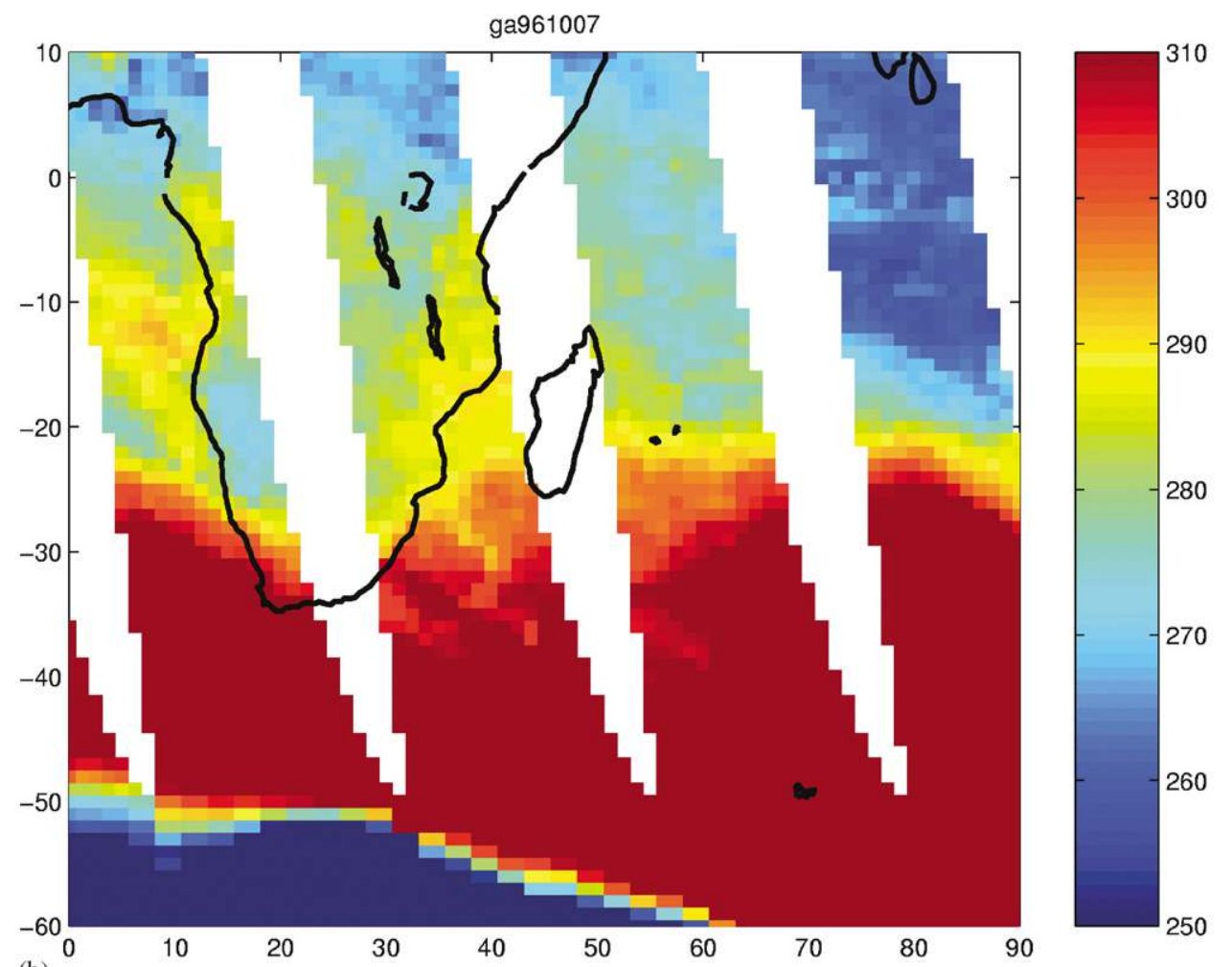

(b)

Fig. 5. Distribution of total ozone as measured by the TOMS instrument for 2 October (a) and 7 October 1996 (b). 
completely detached, the location of the PV maximum at the center of the COL corresponds to an area without cloud, situated to the south of the cloudy area. Thereafter, this cloudy area seems to enlarge and by 8 October the COL corresponds well with the cloudy zone. Machado et al. (1992) have studied this kind of equatorial deep convective cloud over tropical Africa and showed that cloud heights reach $14.7 \mathrm{~km}$. This cloud activity could take part in the convective dissipation of the COL and the subsequent convective redistribution of ozone and humidity, which decreases the vertical contrasts of PV, ozone and humidity (Table 1). Because of the COL dissipation, the dark zone corresponding to the COL area is no longer visible on the 11 October water vapor image (Fig. 4).

Dynamical elements of the study suggest that this COL could have a significant influence on tropospheric ozone over South Africa. If this is true, it is expected that some signatures on ozone and humidity should be visible in the TOMS and MOZAIC data.

The signature of the COL is weak and could be locally perturbed by upper tropospheric clouds. Moreover, this signature is difficult to distinguish from other processes influencing stratospheric ozone variations. But despite these inconveniences, quite strong values of total ozone content are visible at the location of the COL on 2 October, and the signature is more visible, $290 \mathrm{DU}$ on 7 October (Fig. 5). These strong values could correspond to the influence of the COL on the total ozone column.

The European project MOZAIC consists of airborne observations of humidity, temperature and ozone on inservice aircraft (Marenco et al., 1998). The geographical coverage of MOZAIC data extends over the whole globe, and the route Vienna-Johannesburg cuts Africa transversely and passes close to the area affected by this COL. Fig. 6 indicates the concentration of ozone and humidity along MOZAIC flights, which took place before the formation of the COL (25 and 26 September), and during its dissipation (11 and 12 October). The location of the aircraft (latitude, longitude and altitude, Figs. 6e and f) indicates that the aircraft crossed ozone enriched zones on 12 October at 06 and 20 GMT, both near $27^{\circ} \mathrm{E}$. Following the ECMWF analysis (PV map at $330 \mathrm{~K}$ on 12 October), the center of the COL is located near $37^{\circ} \mathrm{E}$ (cf. Table 1), at about $900 \mathrm{~km}$ from the trajectories of the MOZAIC flights. The interpolation of PV along the flight paths display tropospheric values (0.3 PVU, Figs 6c and d). However, the signature on the ozone mixing ratio is significant, with values between 80 and $100 \mathrm{ppbv}$ between $8^{\circ} \mathrm{S}$ and $6^{\circ} \mathrm{S}$ on 11 October (Fig. 6a). Southward of $8^{\circ} \mathrm{S}$ and northward of $6^{\circ} \mathrm{S}$, the ozone values are lower, 80 ppbv or less. On 12 October, the same enhanced ozone signature is visible, although it is spatially restricted between $7^{\circ} \mathrm{S}$ and $6^{\circ} \mathrm{S}$. It seems that ozone is a better tracer of stratospheric air than PV because of diabatic non-conservation of PV (mixing by filamentation, turbulent diffusivity, convection). The characteristic period of the event, about 12 days from 1 to 12 October, is consistent with the hypothesis of non-conservation of $\mathrm{PV}$ and conservation of ozone.

Clustered backtrajectories (Fig. 7) have been calculated starting from the zone enriched in ozone on the MOZAIC flight, and the eastern side of this zone, since the COL is located on this side. Backtrajectories are calculated using three-dimensional ECMWF wind fields. At each running point of the trajectory, wind components (horizontal and vertical) are interpolated in time and space. The trajectory is then determined by iterative advection of the air mass using a 5-min time step. This trajectory model developed at Reunion University has been used in previous studies (Randriambelo et al., 2000). These calculations confirm that the MOZAIC flight has passed just above but within the vicinity of the COL: The black backtrajectories $(250 \mathrm{hPa})$ indicate a southerly movement, after a recirculation near $5^{\circ} \mathrm{S}$, $25^{\circ} \mathrm{E}$, but no clear subsidence. The red backtrajectories ( $400 \mathrm{hPa}$ the altitude of the COL), indicate a subsiding southerly movement over 3 days. Most of the green backtrajectories indicate a southerly movement, and a subsidence 3 days earlier. Because of the low resolution of ECMWF data it is difficult to study the dynamics of an air mass thoroughly. It is necessary to initialize backtrajectories with a mesoscale model to provide better evidence of the stratospheric origin of air masses (Kowol-Santen and Ancellet, 2000).

In order to analyze the fine-scale evolution of $\mathrm{PV}$ missing in the ECMWF analyses, we use contour advection with Dritschel's algorithm (1989). This algorithm has been recently applied to the evolution of RWB and mixing in the subtropics, with good agreement between advected PV and MOZAIC measurements of ozone (Scott et al., 2001). Fine-scale PV on the $330 \mathrm{~K}$ isentropic surface, estimated according to the algorithm, is depicted in Fig. 8, for 12 October, 06 GMT, which coincides with the passage of the first MOZAIC flight. Figs. 8a-d represent fine-scale PV based on initialization for $3,5,7$, and 9 October, respectively. The COL is well modelled by the initialization on 9 October (Fig. 8d). The center of the COL as identified by the algorithm is located near $12^{\circ} \mathrm{S}, 35^{\circ} \mathrm{E}$, slightly to the east of the MOZAIC flight

The simulations initialized on 3, 5, and 7 October display similar results, with the COL not being well reproduced by the advection model for these simulations. This suggests that the most intensive diabatic effect occurs before 9 October. Fig. 8 shows that the COL spins, emitting several filaments in the process. The last filament (created on 8 October) cuts the trajectory of the MOZAIC flight with an intensity more than 1 PVU, near $9^{\circ} \mathrm{S}, 27^{\circ} \mathrm{E}$. Although the advection model is a pure isentropic advection model, the results suggest that an air mass could escape from the COL on 8 October and 

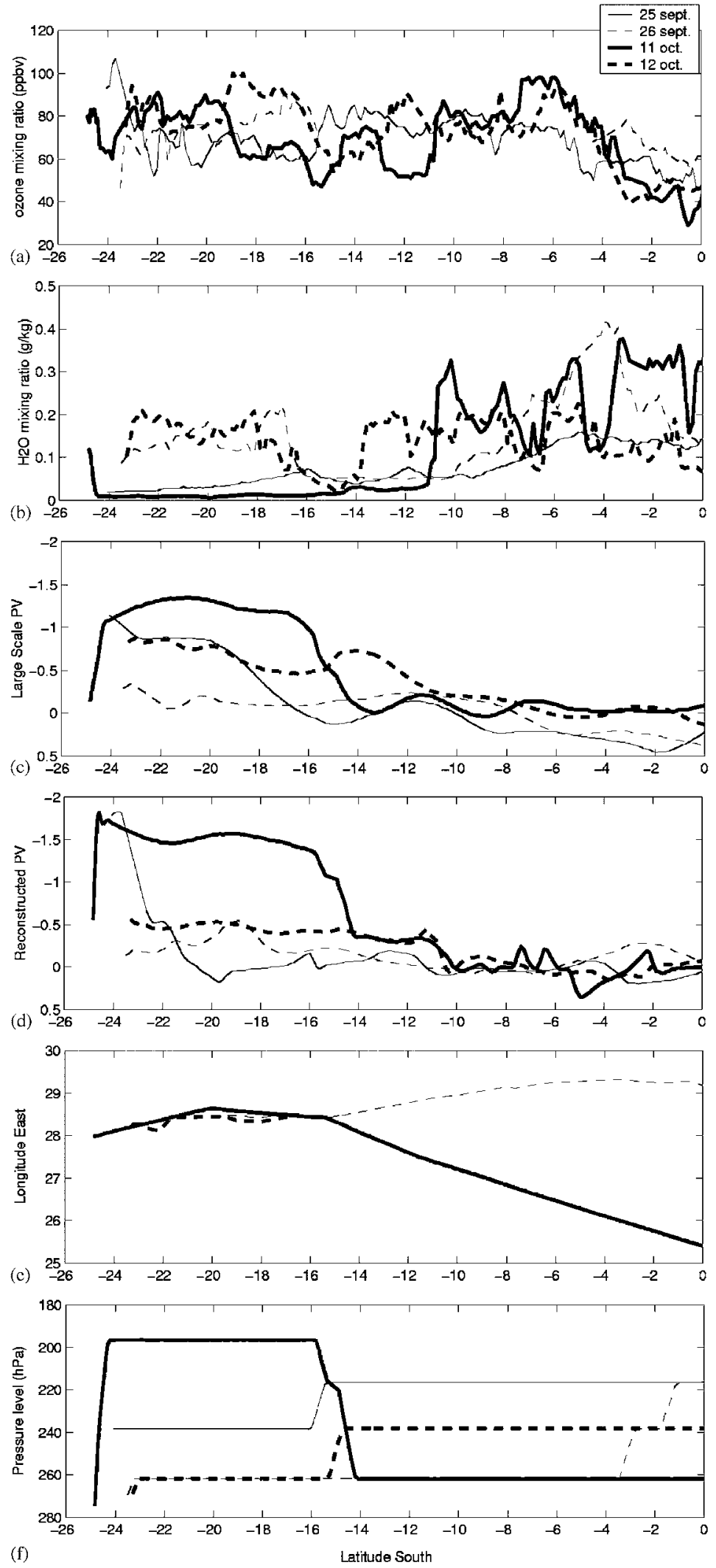
lose PV because of diabatic effects. In short, we then can directly interpret the ozone enhancements on the MOZAIC flights as a net result of the stratospheretroposphere exchange around the COL in the tropical free troposphere, the dynamical character of the stratospheric origin of the COL, as evidenced by PV, having almost totally disappeared.

October is the beginning of the biomass burning period in South Africa. During this period, an ozone enhancement due to biomass burning influences cannot, a priori, be excluded. Moreover, lightning can produce $\mathrm{NO}_{x}$ and, then, through photochemistry, induce ozone generation (Pickering et al., 1993). This influence can also not be excluded, since convective activity is noted close to the ozone peak. However, in our case, it is noted in the MOZAIC data that the ozone-rich air mass, (between $6^{\circ} \mathrm{S}$ and $8^{\circ} \mathrm{S}$ on 11 October) is also very dry, with a very low water vapor mixing ratio at $7^{\circ} \mathrm{S}$, and surrounded by relatively higher values. This is consistent with clouds observed by satellite (Fig. 4), with the stratospheric origin of the air mass near $7^{\circ} \mathrm{S}$ on the trajectory of the aircraft, and with the convective redistribution of 7-8 October. The interpolation of PV along the MOZAIC flight indicates a small maximum in large scale PV at $7^{\circ} \mathrm{S}$, and a clearer signature (2 maxima at $6^{\circ} \mathrm{S}$ and $8^{\circ} \mathrm{S}$ ) in reconstructed $\mathrm{PV}$. These signatures are weak in amplitude (it has been shown previously that the COL is not at its maximum and that its dissipation started on 7-8 October, and that the MOZAIC flight did not pass through the center, but around and over the COL), but these stratospheric signs are persistent over longer time periods than those considered in the statistical study of Price and Vaughan (1992).

\section{Conclusion}

In this study, we have investigated a tropical COL occurring in October 1996 over South Africa, and have studied its impact on tropospheric ozone. This tropical COL differs in structure from the polar and mid-latitude COLs reported in previous studies. In the case presented in this study, there is a complete detachment of the mass of air from its external surroundings, in both the horizontal and vertical planes, and it has a lifetime of about 2 weeks. This is not always true of mid-latitude and polar COLs, where the detachment is sometimes only in the horizontal, and in the vertical the COL consists of an upper level depression where the tropopause is lower than its usual level, but without a clear vertical detachment. There have been a few studies of Northern Hemisphere COLs that show a similar behavior, but in such cases the lifetimes are smaller (less than 5 days for the studies of Ebel et al., 1991; Appenzeller et al., 1996; Langford et al., 1996, and less than 8 days for the studies of Ravetta and Ancellet, 2000 and Gouget et al., 2000). If this kind of structure is not unique to our case study, but is more generally reproduced for other cases of tropical COL, then this characteristic could imply that the mass of air contained in the tropical COL has a potentially more significant impact on tropospheric ozone than other COLs, due to a reduced tendency to return to the stratosphere. Moreover, the lifetime (about 2 weeks) and the size of this event (more than $15^{\circ}$ ) are very significant, and several dynamical elements of the study suggest that the stratospheric air introduced into the troposphere did not return to the stratosphere during the event. Previous studies have suggested that the impact of subtropical COLs on tropospheric ozone is minor. Our study suggests that this impact could be larger than previously thought.

\section{Acknowledgements}

The authors acknowledge the MOZAIC project that is funded by the European Communities, CNRS, Forschungszentrum Jülich, University of Cambridge, and Météo-France and supported by EADS Airbus and the Airlines: Air France, Deutsche Lufthansa, Sabena, and Austrian Airlines who carry free of charge the MOZAIC instruments. Alain Marenco is particularly acknowledged for the major role he played in the creation and development of the MOZAIC project. We thank ECMWF for providing the meteorological analysis, GRTR (University of Strasbourg, France) and Eumetsat for providing the Meteosat data, and NASA for providing TOMS data. The radiosoundings of Reunion Island are funded by the French institute CNRS/IPSL, under the local assistance of Francoise Posny and Jean-Marc Metzger. Jean-Luc Baray gratefully acknowledges Gérard Ancellet, Gérard Mégie, Yves Pointin and Tantely Randriambelo for helpful discussions.

Fig. 6. MOZAIC flights Vienna-Johannesburg and Johannesburg-Vienna on 25 and 26 September 1996, and on 11 and 12 October 1996. Plots of ozone (a) and water vapor mixing ratios (b) as a function of latitude; Calculations of large scale (c) and reconstructed PV (d) interpolated along the flights; Position of the aircraft (longitude (e) and pressure level (f) as a function of latitude). The reconstructed PV data have been calculated by interpolation of meteorological ECMWF data along the aircraft trajectory using the reverse domain filling technique (the MOZAIC III report is available on the MOZAIC web site http://www.aero.obs-mip.fr/mozaic/). 


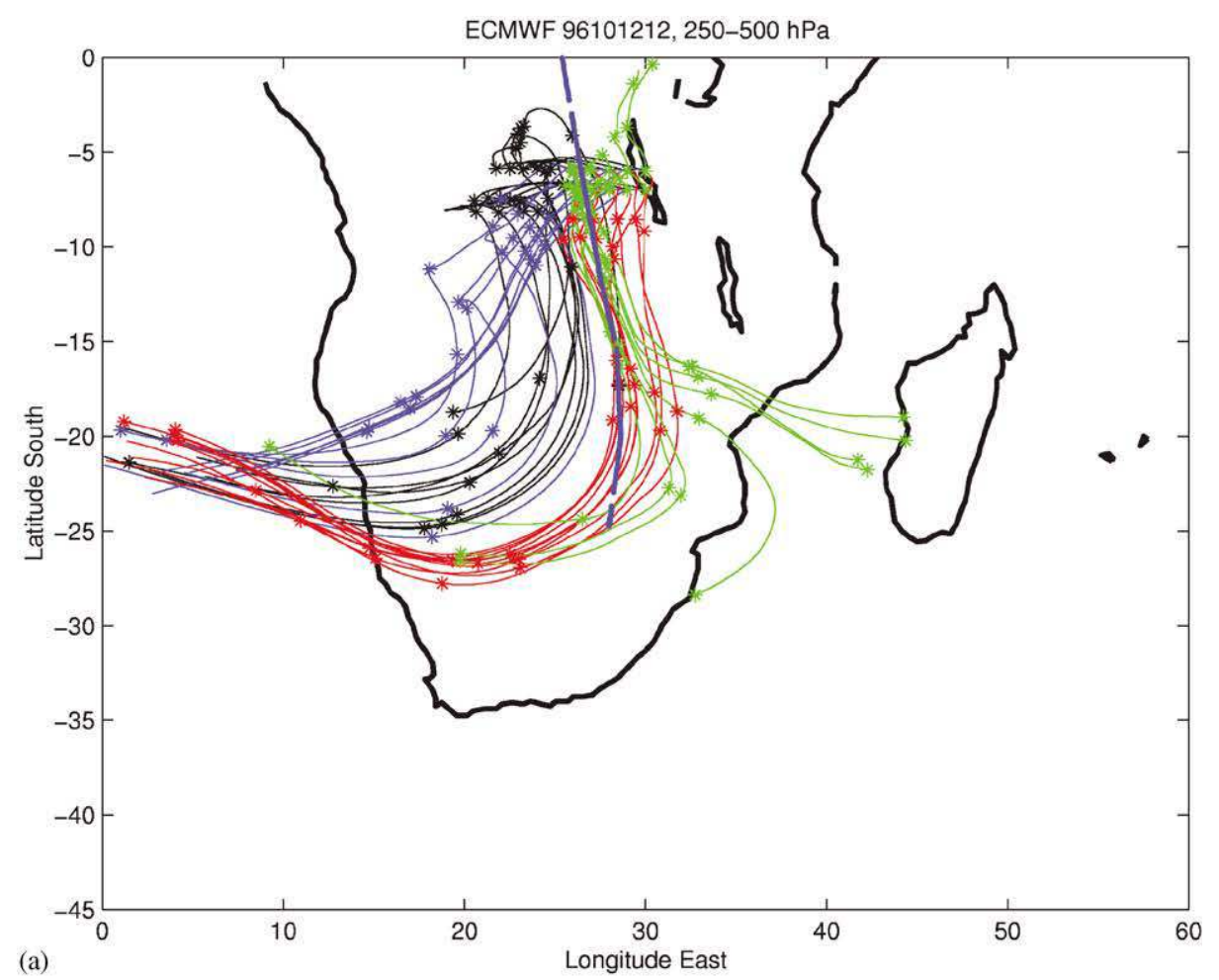

(a)

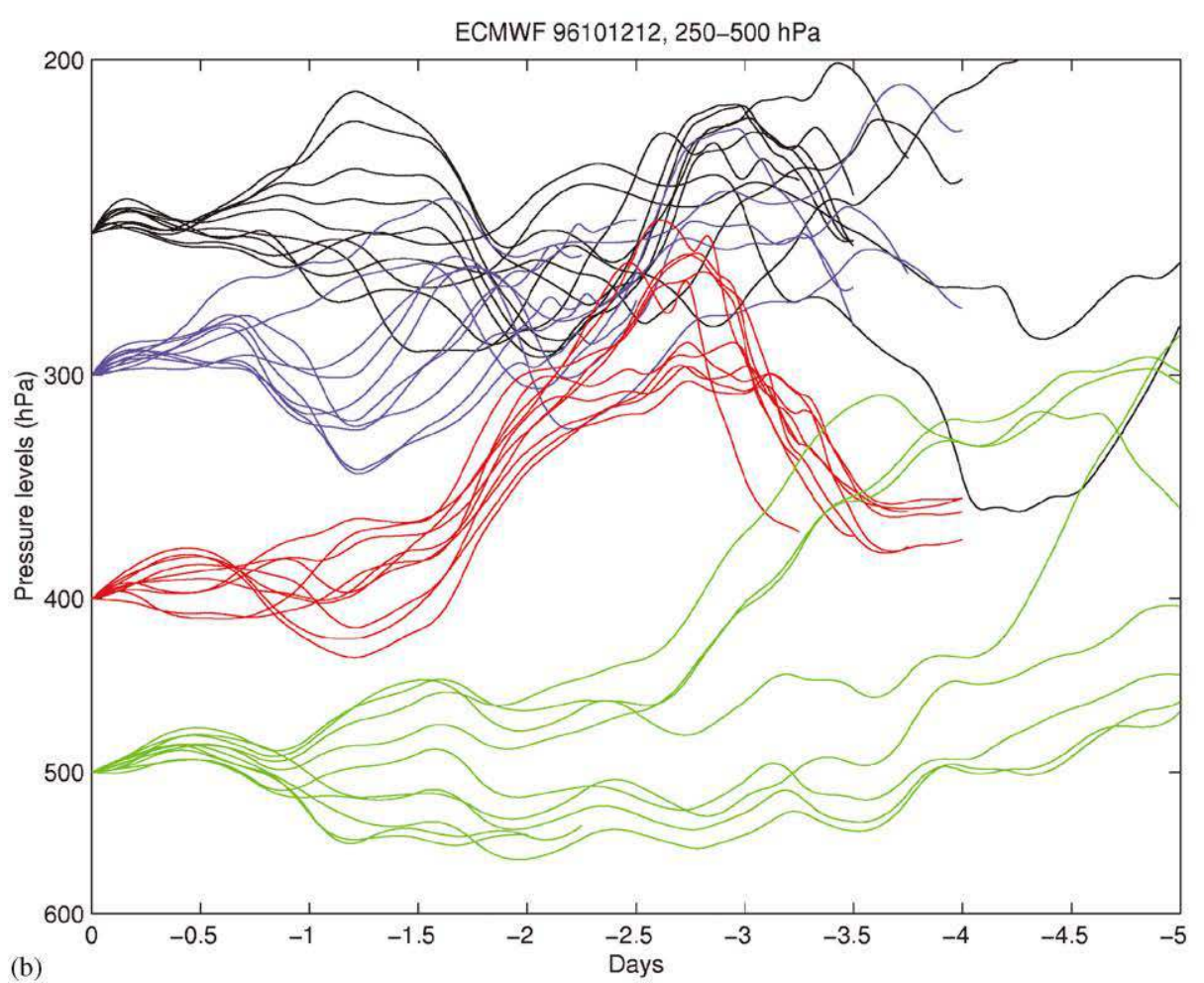

Fig. 7. (a) Cluster backtrajectories ( 10 ending points between $6-7^{\circ} \mathrm{S}$ and $26-30^{\circ} \mathrm{E}$ with a $1^{\circ}$ interval between each point) ending on 12 October 1996, 12 GMT for different levels (black: $250 \mathrm{hPa}$, the approximative level of the MOZAIC flight, blue: $300 \mathrm{hPa}$, red: $400 \mathrm{hPa}$, the level of the COL as seen by the ECMWF analysis and green, $500 \mathrm{hPa}$ ). Each star corresponds to one day backward movement. (b) Altitude corresponding to these transports. 
CAS330 dm=20 IN_T:10/3 12:00z, VE_T: 10/12 06:00z

(a)
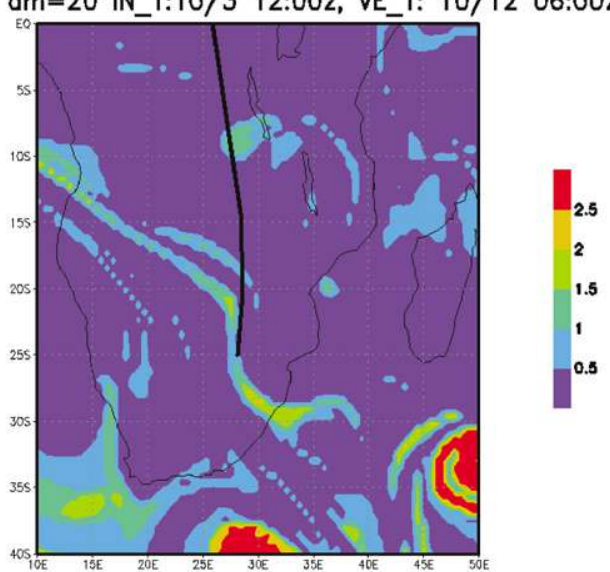

\section{CAS330}

(c)

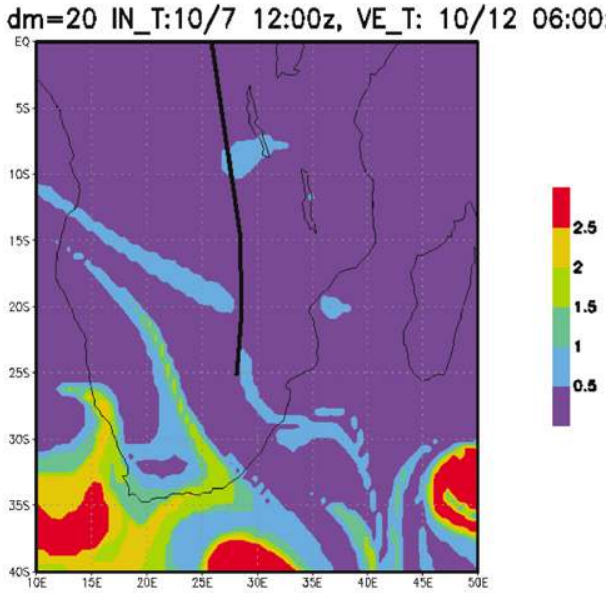

CAS330 $\mathrm{dm}=20$ IN T:10/5 12:00z, VE T: $10 / 12 \quad 06: 00 \mathrm{z}$

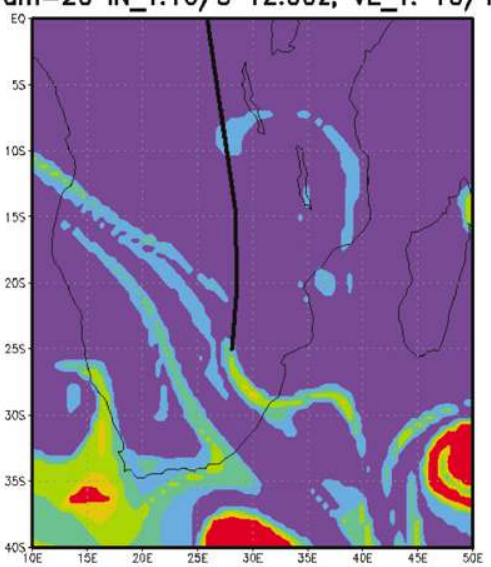

(b)

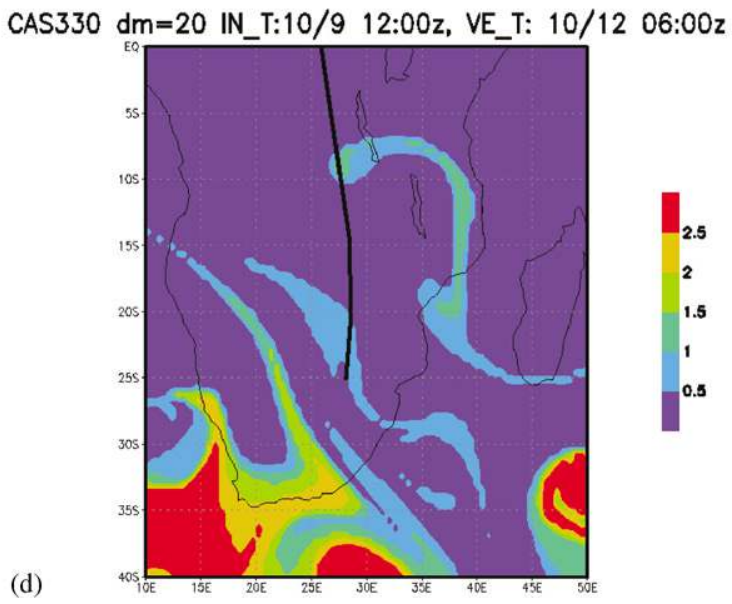

Fig. 8. PV on the $330 \mathrm{~K}$ isentropic surface from a contour advection simulation initialized on 3 (a), 5 (b) 7 (c) and 9 October (d) 1996 at 12 GMT, and ending on 12 October, 06 GMT, coinciding with the first MOZAIC flight.

\section{References}

Ancellet, G., Beekmann, M., Papayannis, A., 1994. Impact of a cutoff low's development on downward transport of ozone in the free troposphere. Journal of Geophysical Research 99, 3451-3468.

Appenzeller, C., Davies, H.C., Norton, W.A., 1996. Fragmentation of stratospheric intrusions. Journal of Geophysical Research 101, 1435-1456.

Barsby, J., Diab, R.D., 1995. Total ozone and synoptic weather relationships over southern Africa and surrounding oceans. Journal of Geophysical Research 100, 3023-3032.

Dritschel, D.G., 1989. Contour dynamics and contour surgery: numerical algorithms for extended, high-resolution modelling of vortex dynamics in two-dimensional, inviscid, incompressible flows. Computer Physics Reports 10, 77-146.

Ebel, A., Hass, H., Jakobs, H.J., Laube, M., Memmesheimer, M., Oberreuter, A., 1991. Simulation of ozone intrusion caused by a tropopause fold and COL. Atmospheric Environment 25A, 2131-2144.
Folkins, I., Appenzeller, C., 1996. Ozone and potential vorticity at the subtropical tropopause break. Journal of Geophysical Research 101, 18787-18792.

Gouget, H., Cammas, J.P., Marenco, A., Rosset, R., Jonquières, I., 1996. Ozone peaks associated with a subtropical tropopause fold and with the trade wind inversion: a case study from the airborne campaign TROPOZ II over the Caribbean in winter. Journal of Geophysical Research 101, 25979-25993.

Gouget, H., Vaughan, G., Marenco, A., Smit, H.G.J., 2000. Decay of a cut-off low and contribution to stratosphere-troposphere exchange. Quarterly Journal of the Royal Meteorological Society 126, $1117-1141$.

Griffiths, M., Reeder, M.J., Low, D.J., Vincent, R.A., 1998. Observations of a cut-off low over southern Australia. Quarterly Journal of the Royal Meteorological Society 124, 1109-1132.

Kentarchos, A.S., Davies, T.D., Zerefos, C.S.A, 1998. Low latitude stratospheric intrusion associated with a cut-off low. Geophysical Research Letters 25, 67-70. 
Kentarchos, A.S., Roelofs, G.J., Lelieveld, J., 1999. Model study of a stratospheric intrusion event at lower midlatitude associated with the development of a cut-off low. Journal of Geophysical Research 104, 1717-1727.

Kowol-Santen, J., Ancellet, G., 2000. Mesoscale analysis of transport across the subtropical tropopause. Geophysical Research Letters 27, 3345-3348.

Langford, A., Masters, C., Proffitt, M., Hsie, E., Tuck, A., 1996. Ozone measurements in a tropopause fold associated with a cut-off low system. Geophysical Research Letters 23, 2501-2504 (and correction in, Geophysical Research Letters 24, 109-110).

Machado, L.T.A., Desbois, M., Duvel, J.-PH., 1992. Structural characteristics of deep convective systems over tropical Africa and Atlantic Ocean. Monthly Weather Review 120, 392-406.

Marenco, A., Thouret, V., Nèdélec, P., Smit, H.G., Helten, M., Kley, D., Karcher, F., Simon, P., Law, K., Pyle, J., Poshmann, G., Von Wrede, R., Hume, C., Cook, T., 1998. Measurement of ozone and water vapor by Airbus In service aircraft: the MOZAIC airborne programme, an overview. Journal of Geophysical Research 103, 25631-25642.

Pickering, K.E., Thompson, A.M., Tao, W.K., Kucsera, T.L., 1993. Upper tropospheric ozone production following mesoscale convection during STEP/EMEX. Journal of Geophysical Research 98, 8737-8749.
Postel, G.A., Hitchman, M.H., 1999. A climatology of Rossby wave breaking along the subtropical tropopause. Journal of the Atmospheric Sciences 56, 359-373.

Price, J.D., Vaughan, G., 1992. Statistical studies of cut-off-low systems. Annales Geophysicae 10, 96-102.

Randriambelo, T., Baray, J.L., Baldy, S., 2000. The effect of biomass burning, convective venting and transport on tropospheric ozone over the indian ocean: Reunion Island field observations. Journal of Geophysical Research 105, 11813-11832.

Ravetta, F., Ancellet, G., 2000. Identification of dynamical processes at the tropopause during the decay of a cut-off low using high resolution airborne lidar ozone measurements. Monthly Weather Review 128, 3252-3267.

Scott, R.K., Cammas, J.P., 2002. Wave breaking and mixing at the subtropical tropopause. Journal of the Atmospheric Sciences 59, 2347-2361.

Scott, R.K., Cammas, J.P., Mascart, P., Stolle, C., 2001. Stratospheric filamentation into the upper tropical troposphere. Journal of Geophysical Research 106, 11835-11848.

Shapiro, M.A., 1980. Turbulent mixing within tropopause folds as a mechanism for the exchange of chemical constituents between the stratosphere and the troposphere. Journal of the Atmospheric Sciences 37, 994-1004. 